"The knowledge that many children in the world's most affluent nation are attacked, maimed, and even killed by rats should fill every American with shame."-President Lyndon B. Johnson, in his congressional message on urban and rural poverty, March 15, 1967.

\title{
Rats in Urban America
}

\author{
JAMES M. CLINTON, V.M.D.
}

$\mathrm{U}$ NTIL RECENTLY, busy public health agencies have given insufficient attention to the problem of rat bites and their sequelae. Cases of rat bite are reported from villages and sparsely settled areas only occasionally, and until recently they have attracted only minimal attention even in densely populated cities. But the increasing frequency of such reports in these cities has focused attention on this phenomenon as an urban problem and made it a source of concern among public health officials and civic leaders.

Until the 20th century, the United States was an agricultural nation. As late as 1930, seven of 10 Americans still lived and worked on farms. By midcentury, however, 14 metropolitan areas had populations of more than a half million; a decade later, 63 cities had passed the half million mark. By 1966 fewer than one person in 10 still claimed a farm address, and this remnant is shrinking every year at the rate of 6 percent of the total farm population (1).

The average annual rate of emigration of nonwhite citizens from rural areas has been $21 / 2$ times greater than that of white citizens. The bulk of this influx gravitates into the central slums and carries rural habits of environmental

Dr. Clinton was formerly a staff member of the Training and Consultation Section, Aedes Aegypti Eradication Program, Consumer Protection and Environmental Health Services, Environmental Control Administration, Public Health Service, Atlanta, Ga. At present, he is an adviser in public health, Wantagh, N.Y. sanitation into an already poorly controlled urban milieu, from whence nearly all rat-bite complaints already emanate. The growing number of bites sustained by slum dwellers attests to the inability of understaffed rodent control agencies, often insufficiently supported by city governments, to cope with the rats that already inhabit the alleys and trash piles.

To assist the cities in reducing this health hazard, Congress, in December 1967, authorized expending Federal funds to reduce rat populations in urban areas. Public Law 90-174, the "Partnership for Health Amendments of 1967," authorized an increase in Federal funds that may be appropriated for grants under earlier health legislation.

\section{Rat-Bite Incidence}

Few States require that all animal bites be reported, and compliance is barely adequate at best. Although the number of persons bitten by rats cannot be determined precisely, health department officials are certain that rat bite is under-reported. The full scale of the problem is as yet only estimated, but some accounting has been made (2).

The New York City Department of Health has one of the best systems for collecting rat-bite data. Although precise year-to-year correlation is impractical because minor criteria changes were made during the development of the system, general conclusions can still be reached. According to information supplied by Dr. George Bernstein of the New York City Department 
of Health, the number of reported cases fell below 600 per year in only 3 of the 9 years from 1955 through 1963 (see chart). Several sampling surveys have indicated that the cases reported to the health department represent fewer than one-third of the actual incidents, since most victims did not seek medical help for minor bites and those treated by private physicians usually were not reported. The slum dweller probably has become so inured to rodents and the conditions associated with their presence that only the most serious cases stimulate reports. Usually he is unaware that municipalities have tax-supported agencies to assist in relieving his situation.

Of the 6 million persons then within the jurisdiction of the New York City Department of Health, the incidence of 600 attacks per year (understated) represents a rate of 10 per 100,000 per year. Nearly identical rates have been estimated by others $(2,3)$. I have collected data from many city health departments which indicate that the previously published reports are representative. In nine large cities responding to requests for rat-bite information, a range of 2.4 to 15.4 bites per 100,000 citizens was established for the 1957-67 period. The wide range represents differences in reporting rather than an actual difference in incidence. If the rate of 10 per 100,000 (on the basis that environmental conditions in congested ghetto areas of the nation are reasonably uniform) is extrapolated to the nation's 140 million city dwellers, an estimated 14,000 persons are attacked by rats annually. This figure is often cited as conservative.

The rat-bite incidence varies little from year to year, but the number of cases has grown with the population and the urbanization of the nation. As emigration from rural regions distends the ghettos, the conditions that can spawn a far higher incidence are exacerbated. The World Health Organization has reported that 20,000 persons are treated in Bombay hospitals for rat bite and rat-bite fever every year (4).

\section{Urban Rat Species}

Generally, the urban rodent problem is caused by three species: the Norway rat (Rattus norvegicus), the roof rat (Rattus rattus), and the house mouse (Mus musculus). Although the
Norway rat is known also as the brown rat and the roof rat as the black rat, these names are misleading because the colors of both species range from light brown to black. These three rodents, of all rodent pests (nutria, cotton rat, and the like), are most often identified with rodent-borne diseases and economic loss through destruction and contamination. All are of Asiatic origin.

As Mediterranean shippers increased their trade with the East during the Middle Ages, the roof rat and the Norway rat were introduced into European seaports from Asia. Subsequently, these rats infested the ships carrying colonists and staples from Europe to the New World. Today, the two species generally are not found in the same region. Whenever the two species meet, the roof rat is soon supplanted by the Norway rat unless the roof rat has an environmental advantage. $R$. norvegicus behaves in many respects almost as a domesticated animal. The familiar laboratory albino rat, our most important experimental animal, is a norvegicus strain. One of the laboratory varieties (Wistar) was derived from wild rats captured on the Philadelphia docks at the turn of the century.

Although the Norway rat is capable of living apart from man, its life is easier in the human environment and it is found less commonly in the rural environment that so much better suits the roof rat. The natural habits of the two species, as well as their environmental eccentricities, also give the roof rat an edge in some situations - the roof rat prefers to nest in high places such as attics, lofts, and trees, while the Norway rat lives in burrows and is therefore easier to reach and destroy than the roof rat.

Unlike some undomesticated animals, the Norway rat accommodates readily to man's scent and presence, exhibits little fear, and will even deliberately approach and make contact with motionless persons. Experienced exterminators report that even when traps and poisons are permeated with "man-scent," they are as effective against the Norway rat as when placed with gloved hands.

$R$. norvegicus accompanied the pioneers to the Western States and established itself wherever man's habits created even slightly favorable conditions. The Norway rat and the 
house mouse, unlike the roof rat, now inhabit all 50 States.

These rodent species destroy property and consume food or contaminate it to the point of uselessness. The U.S. Food and Drug Administration has estimated that rats and mice consume or make useless by contamination as much as 10 percent of America's entire grain crop (5). In this and other ways these rodents cost the American people $\$ 900$ million per year-each of the 90 million rodents accounting for about $\$ 10$ of the total. So ubiquitous is the rat, and so ineffectively is it controlled, that wholesome grain regulations are constrained to allow seizure for destruction only if samples are shown to contain at least one rat excreta pellet per pint of cereal. Lesser contamination, though manifestly undesirable, must be countenanced until control measures already known to be effective are more broadly applied.

\section{Rat-Transmitted Diseases}

Americans also tolerate no fewer than 6,000 cases of rat-transmitted diseases per year $(6)$. The diseases for which rats most commonly serve as either vector or reservoir are salmonellosis, leptospirosis, rat-bite fever, and murine typhus.

Numerous epidemics of salmonellosis have been caused by contaminated food. Although rats are but one of many means of contaminating food, they can contract many of the sero-

\section{Annual totals of reported rat bites in New York City, 1955-63, by boroughs}

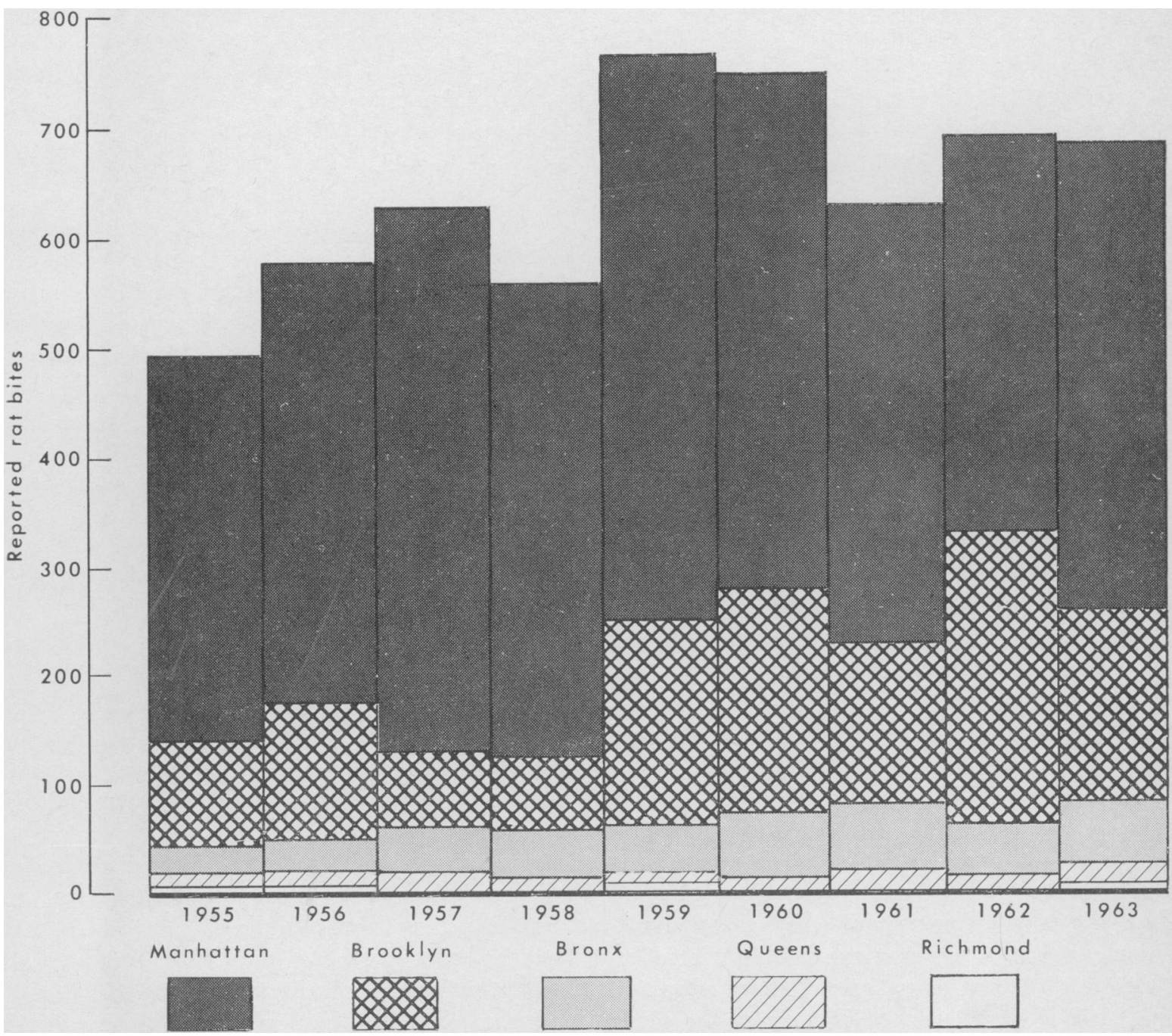


types of Salmonella that are pathogenic for man and have been noted to be efficient vectors in certain milieus such as food-preparation establishments and food-processing plants $(y)$.

Leptospirosis, a worldwide zoonosis, while not a clinical entity in the rat, is a serious illness of man and domestic animals. Because rodent behavior includes perineal licking, rats are likely to have leptospires in the mouth. Several epidemics of leptospirosis have been described among laboratory personnel who work with laboratory rodent colonies in which leptospirosis is enzootic (8).

Clinical specimens collected from Norway rats during several epidemiologic studies have so often indicated prior leptospiral infection that the disease might be considered a "natural" condition in this pest. An unpublished study by the Veterinary Public Health Section of the National Communicable Disease Center in 1964 disclosed that 120 of 201 Norway rats livetrapped in Atlanta were culturally positive for Leptospira icterohemorrhagiae. Subsequent studies have shown that the renal tubules can be heavily infected with leptospires despite negative serologic tests or cultures of either blood or urine.

Rat-bite fever, caused by gram-negative Streptobacillus moniliformis, occurs throughout the world. A study of 87 victims treated at Johns Hopkins Hospital in Baltimore between 1939 and 1943 disclosed that 11 percent eventually contracted rat-bite fever (9). This malady usually produces rash, fever, and other signs several days after a rat bite, but contact with a rat is not essential to transmission; victims have become infected while living or working in ratinfested buildings. S. monitiformis has been found in the pharynges of as many as half of the laboratory and wild rats in which it has been sought $(10)$.

Rats feed on foodscraps and the undigested food particles in feces. There is a positive correlation between the density of rat infestations and the concentration of suspended solids in sewers (11). Although rat infestations are usually found only in sewer systems more than 30 years old or in sewers that have been ruptured by tree roots, sewer rats are not restricted by socioeconomic demarcations. They threaten nearly all urban residents. Rats enter the catch basins of storm sewers while foraging or seeking shelter and are attracted by the sewage in the sanitary system. Today's garbage disposals in homes pour out a bountiful, uniform, and well-balanced food supply for rats. The high protein content that characterizes the more affluent neighborhoods is particularly enticing (11).

From sewerlines rats can make their way into residences through broken grilles on basement drains and even through toilets. The August 1963 issue of Pest Control, a trade journal, lists many cities in which such situations have warranted continual baiting of sewers (12). In 1967 in Atlanta, rat-bite cases in several homes in upper socioeconomic areas could be explained only in such a context, for on several occasions rats were found alive in covered toilet bowls. Investigators speculate that many of the rat bites reported from upper socioeconomic neighborhoods are attributable to rats that have entered through bathroom sewerlines.

\section{Rat-Bite Victims}

An estimated 14,000 cases of rat bite occur each year in the United States. Those of us who have had more rewarding lives can never appreciate the adverse psychological effect of the presence of rats, or the havoc that an infant's rat-mutilated lip or ear can wreak on his personality over the years.

The epidemiology of rat bite is in its infancy, but health department reports have established some generalities.

In cities, rat-inflicted injuries are most common (a) under crowded conditions, (b) in substandard housing, $(c)$ in areas with poor environmental sanitation, or $(d)$ in neighborhoods where rat-infested property is being climinated. This generalization was confirmed by a study covering 54 months in Atlanta; 70 percent of 499 cases were noted to have occurred within 12 of 86 census tracts, all of which met one or more of the four criteria mentioned. Based on these criteria, most municipalities can designate areas in which the incidence of rat bite has been high and-unless checked-will continue to be high.

From 1941 through 1945, some 20,000 cases of murine typhus were reported to the Public 
Health Service. In 1940, Atlanta initiated an active rodent control program to combat the disease. During the next 20 years, the annual incidence of rat bite gradually decreased. A low of 58 attacks $(12.9$ per 100,000$)$ was achieved in 1958 . Then in 1960 , concomitant with demolition of slum housing that preceded construction of two interstate highways through the inner city, there was an increase in the number of rat attacks, with $92(20.6$ per 100,000$)$ reported that year. This record still stands.

In several American cities increased incidence in attacks was reported as an aftermath of destructive rioting during 1967.

IIelpless persons (infants, paraplegics, and persons incapacitated by alcohol, drugs, and other causes) are attacked more often than able persons.

In 1966 in Atlanta, 24 percent of the 54 victims of rat bite were under 2 years of age, but less than 6 percent of the city's population was then in this age bracket (13). (Food around babies' mouths is believed by some to be associated with infant rat-bite cases.)

Frequently, victims are attacked while sleeping. In 80 percent of the 1967 rat-bite cases in Atlanta, the victims were asleep in bed. I have verified the case of a helpless woman attacked by rats while she slept. The victim, an elderly hemiplegic, hemorrhaged extensively from multiple rat-bite wounds and died despite emergency hospital treatment. Her 17-year-old granddaughter asleep in the same room at the time of the attack was unharmed.

In a midwestern city, a $\$ 250,000$ lawsuit has been settled out of court; the complainants had sought damages from their landlord in reparation for rat-inflicted genital injuries sustained by an infant son.

Some persons are likely to be bitten repeatedly and certain body regions are bitten more often that others. In Baltimore, 30 percent of the rat-bite cases reported in 1945 were repeat cases; one child was injured on 11 different occasions (9). During 1967 in Atlanta, 27 of the 91 victims of rat bite were living in households with victims of previous attacks or were themselves victims of earlier rat attacks. A comparison of the anatomical area most often bitten by rats in Atlanta and Baltimore, based on available data, shows similarities, as follows:

$\begin{array}{ccc} & \text { Grady } & \text { Johns Hopkins } \\ \text { Memorial } & \text { Hospital, } \\ \text { Site of bite } & \text { Hospital, } & \text { Baltimorc, } \\ & \text { Atlanta, 1967; } & 1939-43 ; \\ & 91 \text { victims } & 87 \text { victims } \\ & \text { (percent) } & \text { (percent) }\end{array}$

Upper limb_........ 43

Head

Lower limb_....... 18

Thorax-abdomen....

Site not indicated...-.

Persons suffer rat bite most often during the early morning hours. Most American cities report that more rat bites occur between the hours of 12 a.m. and 6 a.m. than during the remaining 18 hours of the day. From a random sampling of cases in New York City in 1966, Dr. George Bernstein noted that of those instances for which a time had been recorded, more than 75 percent took place during the early morning hours (midnight to 8 a.m., 87 victims; 8 a.m. to 4 p.m., 15 victims; 4 p.m. to midnight, 12 victims). This information corroborates the remarks of Dr. Lawrence E. Scheving, a Louisiana State University physiologist who has published many papers on the temporal structures and endogenous rhythms of the physiological functions of $R$. norvegicus. Scheving reported more aggressive behavior in the species during the early morning hours. In a letter in April 1968, he commented as follows :

For more than a decade we have been working with rats, usually maintained under a laboratory regimen of 12 hours of light (0600-1800) alternating with 12 hours of darkness. Because one of our main interests has been this animal's overall circadian time structure, we necessarily must handle them at all hours of the day to obtain the measurements of their various functions. Invariably the personnel who handle these rats agree that the animal is much more antagonistic to manipulation during certain hours of the night (from approximately midnight to 6 a.m.) than during the day when he would normally be resting or sleeping. For example, an experienced handler is more frequently bitten, or comes close to being bitten, during these hours.

One might argue that this is because the handler is less alert and consequently more careless. This latter point may be a factor; however, it is our considered opinion that the reaction observed is actually due, for the most part, to a more endogenous aggressive behavior at night. These claims are certainly empirical, and some type of experiment would be required to qualify the observation. But because practically all measured functions from corticosterone levels in the blood to the biogenic amines of the brain, and even in the animal's 
susceptibility to an anesthetic agent or to a potentially noxious substance in the rat are rhythmic within a 24-hr. scale, we are not surprised to see fluctuation in the animal's response to the stimulus of handling or his aggressive behavior.

\section{Rat Control}

Poisoning, fumigation of burrows, and trapping have never permanently controlled rats; even chemosterilants have not measured up to the promise they offered. Warfarin-resistant rat populations have evolved in Europe. They are sufficiently acknowledged that an area of 400 square miles in the United Kingdom has been sequestered within a 3-mile-wide ring in which regular inspections are conducted to seek evidence and prevent outward migration of the resistant population (14).

The most realistic and practical way to control rats is through environmental sanitationremoving food and harborage to lower the capacity of the environment to support rat populations. This recommendation is based on the findings of many studies in which altered environments have significantly depleted Norway rat populations (15). In summary, these studies have disclosed that increase of a rat population, when plotted against time from the start of an infestation, produces a typical growth curve of which the upper asymptote is located by the amount of food and harborage in the environment under consideration. When the curve approaches this asymptote, its only fluctuations (without other interference) are those caused by changes in the equation of the asymptote itself.

Only 5 percent of the rats that are born in any given year live long enough to be weaned. The density of all rat populations is governed by two reciprocally offsetting factors-fecundity and mortality of these survivors. These factors are in turn directly proportionate to the environmental factors, food and harborage. Animal predation is of negligible importance. Poisoning, trapping, fumigating, and other directly destructive methods of control are but transient interference, for though they enhance mortality they are intermittent and do little to impair fecundity. The remnants of a rat population decimated by any of these methods will, when the interference is withdrawn, quickly expand again to the limits imposed by the environment.
The elimination of food and harborage creates environmental pressure that intensifies intraspecies competition and literally uses the rat to enhance its own mortality and to impair its own fecundity. In any environment, the proportion of reduction in food or harborage acting ing through both governing factors, fecundity and mortality, will be reflected as a reduction in the same proportion of the rat populationregardless of the size of that population. Such environmental control can be practiced without danger to workers or inhabitants, by minimally trained persons, on a scale impracticable for poisoning, trapping, instituting predation, and other directly destructive methods or chemosterilizing. But the food-free, harborage-free environment must be maintained. Unless conditions that favor the rat are completely and permanently eliminated, the animal will survive and eventually reassert itself in whatever numbers the environment will support.

\section{Summary}

Rat-inflicted injuries have become a significant source of concern to public health administrators. Nearly all rat bites are inflicted by the Norway rat (Rattus norvegicus), a pest of Asian origin which is entrenched in all 50 States. This rat accepts human beings as a part of its environment.

Besides exacting a heavy economic toll through waste and contamination, the rat is a health hazard. Leptospirosis, a worldwide zoonosis, is so commonly found in $R$. norvegicus in some areas that it is considered unusual when the spirochete or its antibodies are not demonstrated in the animal.

City health department surveys indicate that rat bite is invariably under-reported; published estimates of rat-bite incidence indicate a rate of 10 per 100,000 persons per year. Many American cities are plagued by a growing population of rats in combination storm and sanitary sewers. Entry into residences is thus possible through plumbing even after foundations, doors, and windows have been ratproofed.

Most victims are helpless persons, typically sleeping infants. Attacks usually occur during the early morning hours.

Proper environmental sanitation, which low- 
ers the capacity of an area to support large rodent populations, is the most satisfactory mode of preventing rat bites.

\section{REFERENCES}

(1) U.S. Department of Commerce : Current Population Reports. Series P-27, No. 37, Apr. 14, 1967, pp. 1-6.

(2) Scott, H. G. : Rat bite : Epidemiology and control. J Environ Health 27 : 900-902, May-June 1965.

(3) Lisella, F. S., Mullen, R. L., and Savage, E. P. : A review of the rat bite problem in Tampa, Florida. J Environ Health 29 : 322-328, January-February 1967.

(4) World Health Organization: Meet the rat. World Health, April 1967, pp. 3-18.

(5) U.S. Food and Drug Administration: Grain sanitation program. April 1957, pp. 2-6.

(6) Scott, H. G.: Operation rat. U.S. Public Health Service, Mar. 25, 1965, p. A-3.

(7) Edwards, P. R., and Galton, M. M. : Salmonellosis.
In Advances in reterinary science, vol. 11, 1967, pp. 2-46.

(8) Stoenner, H. G.: Leptospirosis (ballum) contracted from Swiss albino mice. Arch Intern Med 101 : 606-610, March 1958.

(9) Richter, C. P.: Incidence of rat bites and rat bite fever in Baltimore. JAMA 128: 324-326, June 2, 1945.

(10) Strangeways, W. I. : Rats as carriers of Streptobacillus moniliformis. J Path Bact $37: 4 \mathfrak{0}-51$, July 1933.

(11) Beck, J. R. : Cause and control of sewer rats. Public Works 96:116-118, April 1965.

(12) City sewer rat control across the nation. Pest Control 31 : 9-20, August 1963.

(13) Georgia Department of Public Health Biostatistics Service: Georgia Vital and Morbidity Statistics, Atlanta, 1966.

(14) Drummond, D.: Rats resistant to warfarin. New Scientist 30 : 771-772, June 23, 1966.

(15) Davis, D. E.: The characteristics of rat populations. Quart Rev Biol 28: 373-401, December 1953.

\section{Nurse-Midwives in Alaska}

The first nurse-midwifery program in the Public Health Service is being established at the Alaska Native Hospital in Bethel.

The purpose of the program is to use the services of well-trained nurse-midwives in a pilot project aimed at improving health care of expectant mothers and their newborn babies. The mortality rate of Alaska Native infants is almost twice that in the general population (51.4 per 1,000 live births to 23.7), and complications of pregnancy among Alaska Native mothers are a principal cause of illness and hospitalization. Extremes of climate, geographic isolation, transportation difficulties, poor housing, and lack of basic health information contribute to these problems.

The 55-bed hospital at Bethel, located in west-south-central Alaska, serves a community of about 2,000 persons, mostly Eskimos and Aleuts, and an area population of approximately 12,000 living mostly along riverbanks and the Bering Sea coast.

Under the program at the Bethel hospital the physician will remain responsible for health supervision and management of expectant mothers. The nurse-midwife will be responsible for care of normal patients delegated by the physician, and thus he will have more time for attention to complicated obstetrical conditions and patients with special needs. In the village setting she will teach the importance of prenatal care and family planning to individuals and community groups and participate in parent classes and other health and welfare activities.

The nurse-midwife will refer to the physician any patient who appears to deviate from the normal. She will provide patient support and counseling and will refer patients to public health nurses for followup. 


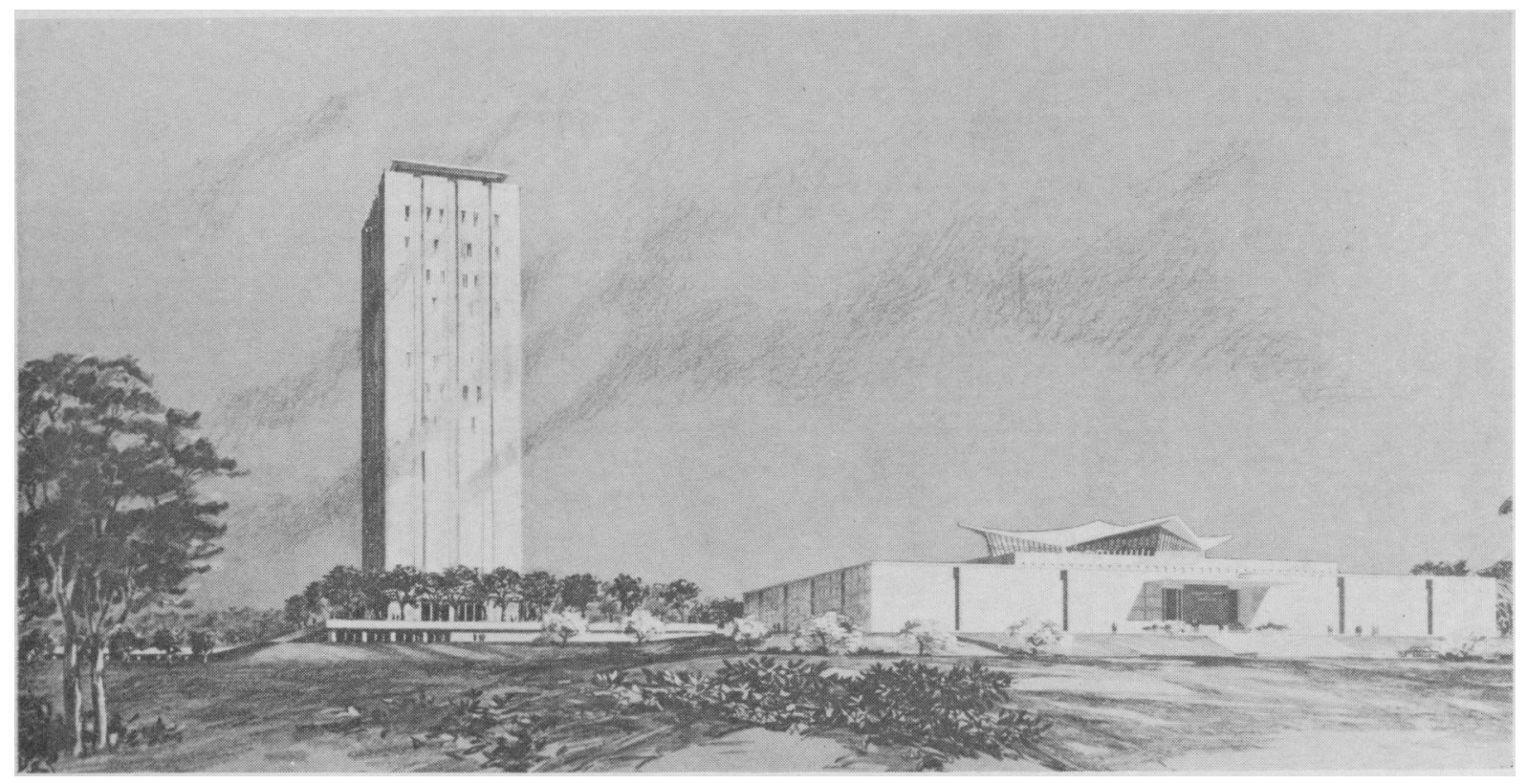

\section{Lister Hill National Center for Biomedical Communications}

The planned National Center for Biomedical Communications, named in honor of Senator Lister Hill from Alabama, will be a part of the National Library of Medicine, a component of the National Institutes of Health, Public Health Service. Preliminary planning calls for a tower-type structure annex to be erected southwest of the Library within the next 4 or 5 years.

On September 15, 1968, Wilbur J. Cohen, Secretary of Health, Education, and Welfare, announced formal establishment of the Center. $\mathrm{He}$ stated that it will serve as the delegated agent for the Department to develop and coordinate networks and information systems to improve health education, medical research, and the delivery of health services.

The Center will house the organizational, managerial, and technical elements of a biomedical communications network, a system being designed to transmit more quickly new information to physicians, scientists, and educators in all of the health professions. The network will use the latest electronic equipment and the most up-to-date communications technology.

Staff planners and the Board of Regents of the National Library of Medicine have been studying how the Center might apply television, satellite communications, films, lasers, and computers for resolution of health problems which are dependent on communications.

The planned Center has been the outgrowth of a number of related actions, recommendations, and legislation by Congress, the medical community, the Library's Board of Regents, and the staff of the Library to meet and keep pace with the expansion of medical knowledge and progress in communications technology.

A feasibility study was performed by the architectural firm which designed the present Library building. The architects recommended that an annex of approximately 360,000 gross square feet of space be constructed to meet the requirements of the Library's activities over the next 20 years. The tower will house the research and development program, the toxicology information program, the new computer system (MEDI.ARS II), and a new graphicimage storage and retrieval system.

Funds requested for architectural and engineering plans are not yet available. However, the Library and its Board of Regents continue to exercise their responsibility to provide leadership in planning prograins for the Center. 